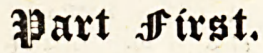

\section{ORIGINAL COMMUNICATIONS.}

\section{ARticLe I.-The Legal and Medical Theories of Mental Disease in}

Criminal Cases. By F. DodD, Barrister-at-Law, Liverpool.

OF the many interesting and important problems connected with medical jurisprudence, there are none equal in interest, difficulty, or importance with that which has recently excited so much and such hot discussion: How far shall the partially insane or mentally diseased be held responsible for acts which, committed by sane persons, would be considered criminal ?

From the consideration of this must be excluded all those points likely to arise in the cases of those crimes committed under the influence of stimulants and narcotics, producing an abnormal condition of, or damaging the mind and brain. The law speaks on such with no uncertain voice; the fact that a man was drunk, or had otherwise temporarily, by his own default, lost control of himself, is no excuse for a crime committed during that time. The reasons for this are obvious and cannot be answered; but that the same stern measure should be meted out to those who, from no immediate fault of their own, are unable rightly to control themselves, or are entirely ignorant of the true nature of their actions, is a proposition so barbarous and outrageous that one can only wonder at the tardiness so abundantly displayed by past generations in moderating the pristine cruelty of the law on this subject by those changes which here, perhaps, it will not be out of place to shortly review.

It will be surprising to many to learn that it is not necessary to go back several hundred years to discover a law dealing with the iusane, harsh and barbarous in the extreme, for so recently as 1723 we find a distinguished judge (Mr Justice Tracy, in Rex $v$. Arnold) saying, "It must be a man that is totally deprived of his understanding and memory, and doth not know what he is doing no more than an infant, a brute, or a wild beast; such a one is never the object of punishment." All others, the same learned judge goes on to say, are responsible for their criminal actions, whether sane or only partially insane, and it is a remarkable feature of the

voL. XXVIII.-NO. vIII. 
law of that period, that although one upon whose sanity there was a doubt, upon whose mind the shadow of some mania, however slight, had fallen, could not make a will disposing of his property, or enter into any contract respecting the most trivial matter, he was liable to answer with his life for an offence against any one of those many rigorous and bloody laws which then prevailed for the repression of crime. 'This atrocious theory, so repugnant to human nature, so merciless to a class already terribly afflicted, bearing with it the sanction of the great lawyers of past ages though it did, could not be expected to have a long term of existence before it, to be passed over and neglected in the many reforms witnessed by the eighteenth century.

But it is not until 1812, in the case of Rex $v$. Bellingham, that we find the judges adopting another, though hardly more humane theory as to the degree of insanity necessary to remove the responsibility for crimes from those who had offended under the influence of mental disease. The adopted formula now was that incapacity to distinguish between right and wrong (not, mind you, in reference to the special act, but generally) should alone be sufficient to excuse. This is clearly a step forward from 1723, but equally clearly it is monstrously unjust to those who, sane enough on most things, abhorring wrong in the abstract as much as the sanest amongst us, are still insane on some one or two subjects. Another step forward must be made, and this was made in 1843 , when a man called M'Naughten was tried for the murder of a Mr Drummond, whom he had killed under the influence of a delusion which obviously induced to the crime. M'Naughten was acquitted, but to settle the law on the subject the House of Lords called the judges before them and submitted certain questions. Then first we have, in the answers, the law laid down that to entitle to an acquittal it would be sufficient for the defence to prove that the prisoner's mind was so far diseased that he did not, when committing it, know the nature and quality of his act, or that he did not know it was wrong.

Unfortunately, however, the judges were not unanimous, and several exceptions to the general rule crept in that have been the subject of much acrimonious discussion, and notably one that if an act committed under the influence of delusion as to existing facts were one which, if the facts really existed as in the mind of the actor, would be justifiable, then no criminal liability should attach; but if, on the other hand, it were one that would be unjustifiable and illegal under any real existing state of circumstances, punishment should follow as in the case of a sane person: e.g., a killing committed in order to obtain revenge for fancied insults or injuries, or because it might seem to the disordered mind a short and ready method of acquiring desired wealth or happiness, would subject the perpetrator to all the usual consequences of murder; but there would be no criminality in one who, to avoid some delusive mor- 
tal or terrible peril, slew the person from whom the danger seemed to emanate. No judicial or authoritative alteration of this statement of the law has been made; but, on the other hand, that it has not commanded the entire approbation of jurists is evident from its not having been accepted by many foreign tribunals, although in many other respects the English criminal law has been adopted. Nor has it commanded the good opinion of the majority of those writers on medical jurisprudence who, being doctors, seem to have completely ignored the impossibility of making general laws applicable to every particular case.

In spite, however, of objectors, the law must be considered as settled so far as the answers go and are unanimous or supported by the majority; but that there is still room for serious doubt on this great question of responsibility is apparent, when we find so great and usually emphatic authority as Mr Justice Stephen, in his able Digest of the Criminal Law, considering as doubtful, in deference to the opinions of Mr Baron Parke (expressed in Reg. $v$. Barton, 3 Cox, C. C., 275), and of Mr Baron Bramwell, now Lord Bramwell (expressed in Reg. v. Haynes, 1 F. and F., 666), the bracketed passage in the following statement of the law:-

"No act is a crime if the person who does it is, at the time when it is done, prevented [either by defective mental power or] by any disease affecting his mind,

"(a.) From knowing the nature and quality of his act; or,

"(b.) From knowing that the act is wrong; [or,

"(c.) From controlling his own conduct, unless the absence of the power of control has been produced by his own default.]

"But an act may be a crime although the mind of the person who does it is affected by disease, if such disease does not, in fact, produce upon his mind one or other of the effects above mentioned in reference to that act."

That a state of finality has been reached in the legal view of mental disease, or that this state of the law is the best possible, even granting the doubts of Baron Parke and Lord Bramwell to be without foundation, can hardly be seriously urged, but that grave fault can be found with it on the ground of harshness or dissonance with justice it would be equally impossible to maintain. Being a part of our criminal system, it will be in all cases construed in favour of a prisoner, and a reasonably elastic interpretation of it will do much to avoid, "on the one hand, that kind of inhumanity towards the defects of human nature, and, on the other side, that too great indulgence given to great crimes," which Lord Hale so earnestly deprecates. That there will be many and great improvements in this as in other branches of judicature it would be idle to deny; but it is by no means so abundantly evident that these can come from those concerned in the making, administering, or practising the law.

A crime may be defined as an act contrary to the law, done 
with knowledge of its nature and of its illegality, and by the word act we understand such a muscular motion as is voluntary, or preceded by the peculiar phenomenon entitled will. Contrast with this the criminal law on the subject of mental disease as stated above, and we find it meeting every possible element of a crime, and refusing to treat as an offence against itself any act in which any one of those elements is lacking. In this state of affairs it becomes difficult to understand or to realize the justice of those clamours as to the exquisite cruelty and inhumanity of the law, which seem to be the outcome of the burning indignation of those who are so ready to raise them. If the law be wrong, it is at least logical, and the error is in the definition of a crime, or the idea of how one should be treated. Granted the premises, it is impossible to see what more can be done by the lawyers until the other great profession, the doctors, will give them some more definite andlet us whisper it-less debatable information on the subject of insanity.

It may be of interest here to note that the civil law, which, as we have seen, was formerly so very strict in its regulations to prevent the mentally diseased being sufferers by their own acts, or dealing with their property so that others would suffer, that it even invalided wills made by those who suffered from mania that would not, in all human probability, have disturbed their right appreciation of their duty towards their issue and relatives, and that although the wills so treated were, so far as internal evidence could go, in entire accordance with natural affection and duty, has been of late years so construed as to bring it more into harmony with that obtaining in criminal matters. Since the classic judgment of the late Lord Chief Justice Cockburn - classic not only on account of the law there laid down and supported by the most masterly reasoning, but also because of its elegant and graceful diction-in the case of Banks v. Goodfellow (5 L. R., Q. B., 549), it must be considered as settled that the mere fact that a testator is subject to delusions is not a sufficient reason for holding the will to be void, unless it shall be proved that they have affected the general faculties of his mind, or influenced him towards a particular disposition of his property. This has since been followed in Smee $v$. Smee (5 P. D., 84); and in the case of Jenkins $v$. Norris (14 Chancery Division, 674) the Court went further, and held that the mere existence of a delusion in the mind of a person making a disposition or contract is not sufficient to avoid it, even though the delusion is connected with the subject matter of such disposition or contract, and that it was a question for the jury whether the delusion affected the disposition or contract.

The theory of the law in regard to the mentally diseased being now made plain, and, it is submitted, abundantly justified, the result of the reduction of that theory into practice remains for consideration. Here, it must be confessed, matters do not pre- 
sent so pleasing an aspect, for rarely indeed is there any case tried in which the plea of insanity is set up, and in which public interest is awakened, without there being a mighty conflict of opinion. That the outside public should take different sides is only to be expected, but that able and learned gentlemen of the medical profession should seize their pens and make the public press a jousting-ground, is a circumstance so strange that we are constrained first to wonder and then to try to understand why this should be so. The only apparent reason is that there are at present many and very forcibly urged doubts as to what constitutes such a degree of mental derangement as to entitle a transgressor to be considered irresponsible. The members of the medical profession say the law is too severe; the lawyers retaliate by saying, if the line be not drawn somewhere, if any relaxation be permitted, there will be no certainty as to the punishment of crime. It is round the standard of those who urge that "moral insanity" should be sufficient to excuse that the battle rages fiercest; and let this daring but hardy band be overpowered, and there can be little doubt peace would be restored. Let us consider what this "moral insanity" is. From the authorities we learn it to be that condition in which the sanction of the moral law is of imperfect or no obligation, and a crime as an offence against right has no terrors to the mind, cognizant though it be of its nature, illegality, and immorality. Is this state sufficient to justify the law in holding its hand? Before answering this question we must remember, and have most clearly impressed upon our mind, that the law never acts vindictively. To punish for the sake only of revenge is no part of its functions, which, rightly and properly considered, are, to so visit a transgression that others may be deterred from the like offence and may see an example of the supremacy of the law; and to so deal with the transgressor that he may not have it in his power to continue in or return to wrong-doing, and that the public may be protected from him. And here it may be proper to remember that it is almost exclusively in cases of murder that the conflict is most severe and that the advocates of irresponsibility have the greatest apparent success ; for when an offence is one that does not bring on itself the dreadful sentence of death, those most interested frequently doubt, as well they may, the desirability of setting up the plea of insanity, which, if successful, is most frequently followed by confinement for an indefinite period amidst the gloomy horrors of a criminal lunatic asylum, a punishment to most infinitely more severe than a sentence of penal servitude.

To the subject of murder we may, therefore, confine our remarks ; and here also we may further digress to point out that the question of capital punishment is but remotely connected, if at all, with the subject under consideration, frequently and powerfully as it has been made use of by some who have written and argued 
strongly in favour of reform in this branch of the law. While there is no alternative for judges when a verdict of wilful murder has been returned by a jury, and a sentence of death must be passed, it is but starting on a bye question, but appealing to a sentimental feeling, to drag in capital punishment. The real question and the only one, is the justification of the verdict, "Guilty of wilful murder " that is to say, if all the circumstances which we have mentioned as necessary constituents of a crime were present. The best way, perhaps, of approaching this point is that already largely adopted by writers on the subject. Certain cases have been the subject of much argument, and none can object if those cases most relied on by the advocates of irresponsibility are dealt with. The principal ones are the Alton murder and Barton's case. Barton murdered a boy under most brutal circumstances and without the slightest provocation, but with the express intention of getting hanged. He was not, and never had been, considered insane, and although, doubtless, of a low mental organization, there was nothing to show any delusion impelling him to the crime. Is there anything here, then, to show that any of the constituents of a crime were wanting? That Barton knew his act to be contrary to the law, and was aware of its nature and illegality, and that it was voluntary, is proved by the motive - to be hanged. The Alton murder was slightly different in facts, but the principle applicable is, it may be contended, the same. The prisoner was a clerk in a solicitor's office, and one afternoon he induced a little girl to go with him into a hop-garden, brutally murdered her, cut up her body, and carefully scattered the fragments. He, again, had never shown the slightest trace of insanity; some of his relations had, but the only fact relied on as showing mental disease in him was that in his diary was found an entry, "Killed a little girl ; fine and hot." That he, also, was fully cognizant of the nature and illegality of his act is clear from the pains he took to scatter the evidence of his crime, and that it was not the result of some sudden and violent paroxysm or frenzy of such a nature as to deprive him temporarily of control is shown by the absence of that fearful remorse which would most surely possess one who had committed such a deed under an uncontrollable impulse. Similar cases might be cited ad nauseam, but the difference would be in detail only. The Golding trial, fresh in the memory of all, is perhaps the most recent one in which moral insanity was strongly brought forward as a reason why the sentence of the court should not be carried out. In all we do not find one single trace of mental derangement previous to the crime for which the transgressor has been put on his trial, nor in that act can we discover that rash disregard of personal safety which might furnish an argument, however slight, of insanity. On the other hand, all we do see is a horrible and unnatural disregard of the feelings of human nature and of the sanctity of human life. 
From these instances, then, from the authorities, and from our general experience, we know that among us there are persons entirely devoid of natural love and affection, for whom right-doing possesses no charm, wrong-doing no terror, save that which the law attaches to it, by whom wanton cruelty towards all incapable of retaliation is displayed, who lie and steal without cause or reason, and yet know all the consequences and penalties which follow their evil works, are skilful in all dealings, and whose mental powers are not infrequently of the most vigorous and commanding order. For holding such responsible for their actions the law is, we are told, harsh and unjust. We have seen that, whether harsh and unjust or not, it is at least logical. Can the same be said of the would-be reformers? What is "moral insanity?" Is it anything else but imperfection of moral character? Surely nothing else. All who commit offences, of whatever degree, are clearly not perfect in their moral character. Therefore we get to this conclusion: All criminals are to escape punishment, because their moral organizations are proved by their crimes to be imperfect, i.e., they are "morally insane," and the greater disregard for right and wrong they have shown, the greater their "moral insanity." A conclusion thus absurd leaves but a poor impression of the reasoning of the advocates of irresponsibility in cases of "moral insanity," however much their zeal may command admiration and their motives respect. One is almost impelled to fear that there is much truth in the assertion that mental disease is infectious, and that some of those who have devoted so much time to the study of madness have not entirely escaped a slight touch of the disease.

It is satisfactory to find that this doctrine of moral insanity has been invariably denounced by the judges, and even some of its advocates admit that it has sometimes been used to shelter an atrocious criminal. Whether it will ever be reduced to such proportions that judicial notice can be taken of it is doubtful; but at present, aiming as it does at the root of all order by showing that no law that punishes a wrong-doer for his transgression can be just, it is rather to be regarded as one of the most remarkable theories ever set up, absurd in its premises, and monstrous in its conclusions, a truly wonderful instance how far enthusiasts will go when once fairly mounted on their hobby-horses, and a proof of unregulated and unreasoning zeal little to be expected in those whose profession would seem to incline them towards the severest mental control.

Having now considered the doctrine of "moral insanity" in its relation to the criminal law, let us shortly examine the operation of our judicature in those more simple cases where a defence of mental disease of a pronounced and acknowledged type is set up. Here it is to be greatly feared that the results are not all that might be desired and expected. The law, as laid down, is appar- 
ently sufficiently'simple and plain, but its application seems to be difficult; too much so, in many instances, there are only too many reasons to believe. As in treating the other branch of the subject instances were cited, it will be as well to follow the same plan here, and mention a case which, although it has not hitherto been mentioned in any work on the subject, created a great impression in many minds at the time.

A gentleman, aged between 40 and 50 , and who previously had borne a high character, was placed on his trial for attempting to murder his children and to commit suicide. A letter was put in evidence by the prosecution, wherein the prisoner said he was taking them to meet his first wife, who had died some years previously. She was always calling them and him, and when they came she would lead them into the presence of the Saviour, and they would all then enjoy everlasting happiness. When charged, he admitted his intention "to take the children," and made a long, rambling statement that "he could not help it; his wife, who was an angel, told him to do it, and she must know better than any men." Now, at the first sight, all this seems conclusive evidence of insanity. Doubtless he knew his intention to be illegal-he had taken precautions against interruption-but did he consider it wrong, i.e., productive of divine punishment? This is, of course, the real test, for earthly law must, even with the sane, give way and be subservient to the divine will when there is an apparent conflict. How much more, then, in the case of a mind diseased! The necessity of obeying the behests of the spirit of his dead wife must inevitably have overshadowed all other considerations, and mere earthly obstacles to such obedience must have been impatiently surveyed and peremptorily swept aside. There is, however, another consideration : might not this letter be a mere cunning device to avoid the consequences of his crime if it failed, and the subsequent statement a further and consistent development of the same scheme? They were both the work of the prisoner, and to rebut the presumption of law, that every act is done with intent and knowledge of its nature, stronger evidence and less tainted must be produced. Then it was proved that the prisoner's parents had been eccentric, although never distinctly insane. He himself had been considered a strange lad. At the age of 14 he received a severe injury to the head. His first wife, the one mentioned in the letter and statement, had died somewhat suddenly, leaving him with infant children. His second wife, formerly a servant in his employment, had turned out a confirmed drunkard; and at the time of the attempt he was financially embarrassed. In addition it was also proved that although clever at his occupation, the tedious and wearing one of a hack writer to daily and weekly journalism, he occasionally wrote the most arrant and incoherent nonsense.

After hearing all the evidence the jury found a verdict of guilty, 
and he is now undergoing a sentence of penal servitude. Before going further, let it be clearly understood that all the evidence in favour of the plea of insanity was undoubtedly true, and was accepted as such by the learned counsel for the prosecution. In the face of these facts the question arises, Was the prisoner rightly convicted? To answer this accurately many points must be considered; and first let us deal with the eccentricity of his parents. The doctrine of hereditary insanity is too well established to need proof or comment here. But is eccentricity a symptom of insanity or mental disease? Not in all cases, but in very many it appears to be so, and instances are not infrequent in which it has seemed to act in some degree as a safety-valve. When the eccentricity has been humoured, all has gone well; a sudden check or violent shock has resulted in pronounced insanity. On this point Dr Maudsley, the professor of medical jurisprudence in University College, London, says, in his work on mental responsibility:- "In families, some members of which have displayed decided insanity, other members have been eccentric. Secondly, eccentricity, after lasting for a time as such, has culminated in insanity. Thirdly, monomaniacs who are known to be insane on certain subjects are often eccentric in their whole conduct. And, lastly, persons who have been decidedly insane, having laboured under one of the recognised forms of mental derangement, often remain eccentric during life after their reputed recovery." So clear a statement from such an authority should be sufficient, but Dr Maudsley says later on, speaking of eccentricities:-They are a vicarious relief, a sort of masked madness." Here, then, we have an emphatic symptom of insanity. True, it is not conclusive, nor is it necessary that it should be so. There are other questions to be discussed before the main issue of the prisoner's sanity or insanity can be considered. It is well known to all who have had any experience in cases of insanity, how great a difference physical injury to the head may make in the mental health and moral character. Dr Wigan says, and Dr Maudsley cites him with apparent approbation, "I firmly believe that I have more than once changed the moral character of a boy by leeches to the inside of the nose." More recently, - so late, indeed, as 19th June 1882,-we have an instance in the public press. A police constable, in the April preceding, was severely beaten about the head with wooden cudgels. For a long period he was ill, and two months after the injury was inflicted he became insane, and a homicidal tendency, so violent that it was necessary to confine him, was developed.

Remembering this, then, the injury done to the head of the prisoner becomes a point that must be borne in mind, and one that helps materially towards the solution of the problem. Then the sudden loss of his first wife, the terrible vice of his second, and his financial position, are each of them sufficient to overthrow the minds of many who live and die with all the repute of perfect

VOL. XXVIII.-NO. VIII. 
sanity, never having had to pass through any terrible ordeal. How much more, then, one with such a trembling balance, ever inclining and being forcibly drawn one way, and only kept in apparent equilibrium by the hard and continuous work of one who had little time for self-communion or to permit his thoughts to run in any groove but that necessary for his occupation! To do his work at all he must have exercised all his powers of application, and that that was not at all times sufficient, doubtless being weakened by the constant strain, is demonstrated by failure at times to produce that which he desired.

To enlarge on the several points mentioned is unnecessary. It is clear, almost beyond possibility of doubt, that the brain was diseased, and there is almost an overpowering presumption in favour of the supposition that his first wife was a frequent subject of his insane thoughts. Here, then, is the connexion between his insanity and his crime. Why was he convicted? What evidence to meet this was called? What theory was set up? None. The prison surgeon, doubtless an admirable and learned member of his profession, was the only professional witness for the prosecution, and he merely said he had conversed with the prisoner, and could find not the slightest traces of insanity. Probably so. He had talked on general subjects, and on those the prisoner was, like most of his profession, well informed, and likely to talk sensibly enough. The jury, searching for guidance, followed the surgeon (and none can blame them), and the judge, as almost in duty bound, accepted his evidence implicitly.

The injustice done to the prisoner in this case is not without many parallels. The only difference between it and many others is the presence of so many symptoms of a diseased mind, without any overt act of decided insanity, preceding the offence for which the prisoner was placed on his trial.

Here, then, we have evidence, if, indeed, any is needed, that many of the mentally diseased suffer by the operation of the criminal law, but it is not at all evident that the blame is on the law. Is it not rather obvious that the fault is on the side of that other profession which is supposed to have the insane under its especial care, from the ranks of which the agitators for reform of the law are mostly gathered?' A change must come, and the students and professors of mental science must inaugurate that change. Luckily there are already those who are doing heroic work in this direction, and, by patient study of the brain and its functions, and by temperate expressions of opinion based on unwearied and skilful examinations, are doing more day by day to ameliorate the lot of the mentally diseased than has been done in generations by those zealots who, by claiming hopeless concessions, abusing judges, and indulging in wild tirades against the law, with an occasional tilt at fox-hunting, capital punishment, and other subjects not immediately, if at all, connected with mental disease, 
have aroused a strong feeling of distrust of them and all their works. A bad cause gains nothing by such wild invective or such discursive advocacy as they have employed, and it is more than likely that a good cause is damaged by it. Napoleon's injunction, "Mais surtout, point de zèle," is good advice for them, and it will be well for them if in future they will remember it.

There is another point connected with this subject, which, although the connexion is not a very intimate one, may be touched upon, and that is, how far does the action of the Secretary of State for Home Affairs tend to remove any cause of complaint in the cases of the mentally diseased? No doubt the judges and medical gentlemen of the very highest standing are consulted, but to the public mind very little satisfaction is given, and that because the Home Secretary is practically a judge who acts on private information; and since the days of the Star Chamber a secret tribunal has been hateful to a people accustomed to have all disputed cases tried in open courts to which the press and the public are admitted. No doubt the evidence on which a decision is formed is of the most cogent character, but there is no direct overwhelming proof that it is; and if an alteration could be made by which the question of sanity or insanity could be tried as publicly as the other question of the doing or not doing of a certain thing, it would give greater satisfaction than the present method can ever do.

In conclusion, then, we have the necessity of such a reformation as will remove two causes of scandal-the improper punishment of those who, by reason of mental disease, are unable of rightly appreciating the nature and consequences of their actions, and the disputes and outcries in those cases in which persons are rightly called upon to answer for their crimes. As the necessity is twofold, so by efforts in two directions the reform may be accomplished. Firstly, and principally, by the more systematic study of mental disease, so that all doubts may be removed, and technical witnesses be able to speak as firmly and with as little fear of contradiction as now in physical cases,-a work surely worthy of the greatest and truest philanthropist, the amelioration of the sad lot of those who have entered into the skirts of the dread hailstorm, worthy, too, of the mightiest intellect, the making of some safe path through the slough of ignorance, the dispelling of those fogs and clouds which have so long hindered and impeded those who have honestly and earnestly endeavoured to reach the true solution of this great enigma aided by such Will-of-the-wisp-lights as could be got from watching instances without studying causes. That this branch of the necessary reform is receiving attention is evident from the many thoughtful works on the subject issuing from the medical press. It is not too much to say that the day is not far distant when it will be possible for experts to speak as positively on the state of the mind, to diagnose as accurately in mental cases as now is daily 
done in less subtle matters. These efforts will be aided and their effects enhanced by the second branch of the reform, i.e., by such an alteration in our legal procedure as will allow the question of the mental condition of a prisoner to be tried before those capable of judging, in open court, on proper evidence. How this is to be done is for others to decide. It is enough for us now to merely suggest a plan, and ask if this desirable consummation could not be attained by the appointment of medical assessors to sit with and aid the judge, in the same way as nautical assessors now assist the judges of all courts having jurisdiction in Admiralty cases with their knowledge and experience in all cases requiring a knowledge of nautical matters and skill. It would not be necessary for the medical assessors always to be present. Their attendance might be secured by notice from those entrusted with the defence of a prisoner. They might sit at the same times as the jury, who would then be relieved from a frequently very onerous portion of their duties, the deciding as to the condition of a prisoner's mind, or they might be called in to a second trial if a jury had found a prisoner guilty of doing something, to find whether that doing was done while the prisoner was in full possession of his faculties. The other details would be equally simple, and the advantages obvious. Witnesses could be asked by cross-examination, and the inclination of a tender-hearted individual to somewhat strain the truth from pity of a prisoner or a prisoner's friends would be repressed.

Whether there is anything in this suggestion it is for others to judge; but, whether in this direction or in any other, something should be done, and that quickly. Humanity demands it, and the sooner this demand is complied with, the sooner shall we feel we have done something to lighten the grievous burden of those most deserving of our pity, most sadly afflicted, and the sooner will those disputes between experts cease to be so rancorous, and the defeated disputants cease to fill space with those cries of injustice, legal murder, etc., which, though little heeded, leave an unpleasant fear behind that it is just possible some poor sufferer has been done to death wrongfully through the operation of the criminal law.

\section{ARTICLE II.-On a Form of Loss of Memory occasionally following} Cranial Injuries. By Joseph BeLL, Surgeon to the Royal Infirmary.

(Read before the Medico-Chirurgical Society of Edinburgh, 16th January 1883.)

THE subject of the present paper, so far as I can discover, has attracted the attention neither of practical surgeons nor of psychologists; and yet I believe it is one of very considerable interest, both practically as a diagnostic symptom of some value, and scientifically as bearing on the question-the very difficult question -of what memory is. 